\title{
LA ENSEÑANZA DEL CUERPO HUMANO EN EL NIVEL INICIAL
} TEACHING THE HUMAN BODY AT THE INITIAL LEVEL

Recibido:20-04-2012

Por: María Josefa Rassetto y Graciela Mabel Maldonado ${ }^{1}$

\section{Resumen}

En este artículo se expone una experiencia que se desarrolló en el nivel inicial (sala de cinco años), en una escuela de la ciudad de General Roca, provincia de Río Negro, Argentina. Se presentan los avances en el aprendizaje de los niños y niñas en torno al tema "El cuerpo humano". Para el análisis de la información se utilizaron los dibujos y la interacción discursiva de siete actividades en clases de Ciencias Naturales. Los resultados muestran que los niños son capaces de avanzar en el proceso de conceptualización, complejizando sus ideas sobre las partes del cuerpo humano, cómo está formado, la función de los huesos.

Palabras clave: enseñanza, cuerpo humano, nivel inicial, ciencias naturales.

\section{Abstract}

This paper describes an experience developed in the initial level (five years), at a school in the city of General Roca, Rio Negro Province, Argentina. Shows progress in learning to children around the theme "Human Body". For the analysis of information were used pictures and discursive interaction of seven activities in natural science classes. The results show that children are able to advance the process of conceptualization, complexity it his ideas about human body parts, how it is formed, the function of bone.

Keywords: Teaching, human body, initial level, natural science.

\section{Contexto de la experiencia}

La experiencia que presentamos se desarrolló en una sala de 5 años en una escuela de la ciudad de General Roca, provincia de Río Negro, Argentina, con veinticinco alumnos. En esta provincia, el nivel inicial está regulado por la Ley provincial $\mathrm{N}^{\circ} 2444$ y está destinado a niñas/os de cuatro y cinco años. Cotidianamente se denomina Jardín de infantes a la institución que se ocupa de este nivel educativo. Generalmente, los jardines de infantes tienen inmueble propio y funcionan de manera independiente de la escuela primaria, aunque aún hay algunas salas que comparten el mismo edificio.

${ }^{1}$ Docentes e investigadoras de la Facultad de Ciencias de la Educación - Universidad Nacional del Comahue. Irigoyen 2000 (CP 8324) Cipolletti. Río Negro. Argentina. Email: mirassetto@hotmail.com 
Por su parte, el currículo del nivel inicial define a la escuela como centros de aprendizaje y se constituye como espacio de apropiación de contenidos significativos y socialmente válidos. En referencia a la construcción del conocimiento, sostiene que la tarea pedagógica debe potenciar en el niño la complejización del pensamiento y los procesos de razonamiento. En este sentido, establece como objetivo prioritario "garantizar el derecho al conocimiento que tiene todo niño independientemente de su situación socio económica familiar" (Diseño Curricular, Río Negro, 1996). Desde esta perspectiva se estructuran las distintas áreas curriculares. Los conocimientos de las ciencias naturales están contemplados en el área "Campo de conocimiento de la realidad natural y social", y entre sus propósitos se plantea: "Favorecer el conocimiento, valoración y cuidado del propio cuerpo y el de otros seres vivos, estableciendo semejanzas y diferencias que permitan reconocer las especificidades de cada uno y el conocimiento de las relaciones que se establecen entre ellos y el medio" (Diseño Curricular, Río Negro, 1996).

En este contexto interesó indagar cómo se enseña el cuerpo humano y qué ideas construyen los niños y las niñas sobre el tema; para ello, se seleccionó una docente que enseñe el tema y se comprometa con el diseño y la puesta en práctica de una propuesta didáctica construida en forma colaborativa con el equipo de investigación.

\section{Fundamentos teóricos de la propuesta didáctica}

Para Vigotsky (2009), los/as niños/niñas en el nivel inicial son capaces de representar por medio del dibujo todas aquellas cosas que conoce y va profundizando, modificando y aprendiendo. Así por ejemplo, dibujan a la persona vestida, pero incluye al mismo tiempo las piernas, el estómago, una cartera con bolsillo, e incluso dinero. La memoria de un/a niño/niña no consta de una simple pintura de las imágenes representativas; por el contrario, posee cierta predisposición a emitir juicios que están investidos con el lenguaje. Así se puede comprobar que el dibujo no es más que un lenguaje gráfico que surge a partir del lenguaje oral.

En el contexto de estas ideas, el concepto de la zona de desarrollo próximo (ZDP), entendido como aquel espacio imaginario ocupado por las potencialidades del aprendizaje compartido, en relación al desarrollo cognitivo ya adquirido por el niño (Benlloch, 1992), permite comprender: 1) Que los niños puedan participar en actividades que no entienden completamente y que son incapaces de realizar individualmente; 2) Que en situaciones reales de solución de problemas, no haya pasos predeterminados para la solución ni papeles fijos de los participantes, es decir, que la solución está distribuida entre los participantes y que es el cambio en la distribución de la actividad con respecto a la tarea lo que constituye al aprendizaje; 3) Que en las ZDP reales, el adulto no actúa solo de acuerdo con su propia definición de la situación, sino a partir de la interpretación de los gestos y habla del niño/a como indicadores de la definición de la situación por parte de este; 4) Que las situaciones que son "nuevas" para el/la niño/a no lo son de la misma manera para los otros presentes y que el conocimiento faltante proviene de un ambiente organizado socialmente; 5) Que el desarrollo está íntimamente relacionado con el rango de contextos que pueden negociarse por un individuo o grupo social.

Por su parte, Tonucci (1988) sostiene la hipótesis de que los/as niños/as, desde pequeños, van construyendo teorías explicativas de la realidad de un modo similar al que utilizan los científicos y afirma que hacer ciencia no es conocer la realidad, sino intentar conocerla. De ahí el propiciar en los niños posibilidades de investigación, que se funden en criterios de relatividad y no en dogmas. Esto significa que hay que ayudar a los niños a darse cuenta que saben, de que también son constructores de 
teorías y que deben poner estas teorías en juego para saber si les sirven, o si es necesario modificarlas para poder dar una explicación a la realidad que los circunda.

Por otro lado, desde la perspectiva de la maduración intelectual, el dibujo del cuerpo humano es utilizado en el test gráfico del dibujo de la figura humana para estudiar la relación de la edad y la maduración de las niñas y los niños (Casullo, M., 2006). Desde esta perspectiva, la complejización de las figuras humanas, dan cuenta del desarrollo intelectual que se puede promover en los espacios escolares.

\section{Desarrollo de la propuesta didáctica}

La propuesta didáctica fue diseñada con la finalidad de desarrollar procesos de construcción de explicaciones y representaciones en niños y niñas en contenidos curriculares sobre el cuerpo humano. El enfoque de la propuesta parte de considerar que los niños pequeños tienen un papel fundamental en la construcción de su conocimiento y que esta construcción no se logra únicamente mediante su participación en actividades lúdicas, sino que debe propiciarse la estructuración de elementos conceptuales que lleven al establecimiento de relaciones causales 0 relacionales por medio de la explicitación de sus ideas. Este desarrollo se logra en una situación que favorezca una rica interrelación con el maestro, así como entre pares.

Las actividades se organizan en torno a tres elementos centrales: 1) dar cuenta de las partes del cuerpo en general y luego profundizar en las partes de la cara; 2) identificar los componentes del esqueleto; 3) reconocer órganos internos. Para el desarrollo de los contenidos la docente puso a disposición de niñas/os una gran cantidad de actividades y de materiales. La carpeta de experiencias de los alumnos fue el espacio principal donde se registraron sus ideas y en la cual se expuso todo el proceso realizado, además de funcionar como un referente para la continuidad de las actividades.

La idea de trabajar con actividades de ciencias que pudieran activar la ZDP promovió la organización de tareas de mayor complejidad para permitir que los niños y las niñas logren complejizar sus conocimientos. Para ello, se propusieron actividades que tuvieron como punto de partida la reflexión conjunta y el trabajo entre pares para permitir el intercambio, la discusión y argumentación así como la manipulación y el contacto directo con material concreto.

\section{Actividad I. Partes externas del cuerpo}

A partir de una canción, "Partes del cuerpo"2, los niños y las niñas forman una ronda; a medida que cantaban, identifican las diferentes partes de su cuerpo.

La actividad no se presenta formalmente como una indagación de ideas previas, pero sin dudas lo es. Carece de una estructura rígida y preestablecida, pero los alumnos tuvieron que estar atentos a la canción para poder ir mostrando las partes de su cuerpo. La canción se presenta como un recurso motivador para iniciar el tema.

\footnotetext{
${ }^{2}$ Esta canción se puede encontrar en : http://www.youtube.com/watch?v=eRAL-Xpvfnl
} 


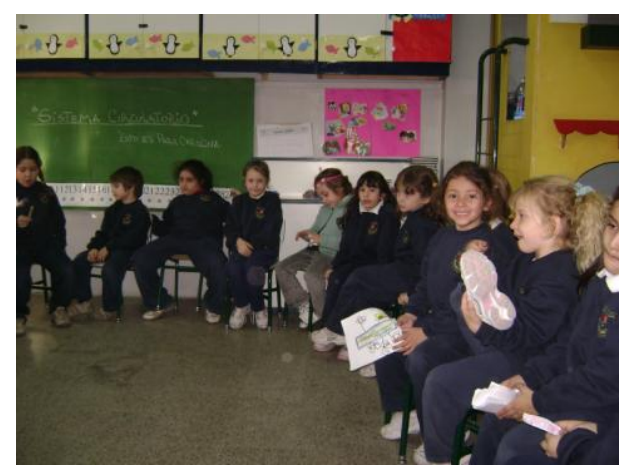

Foto 1: En ronda, niños y niñas cantan e identifican las partes del cuerpo

\section{Actividad II. Dibujamos las partes del cuerpo}

La docente le entrega a cada niño y niña una hoja en blanco y les solicita que dibujen su cuerpo. A medida que terminan la actividad, la docente les retira el dibujo y los acomoda sobre una pared, fijándolos con un gancho. Inmediatamente la docente les solicita que trasladen sus sillas al centro del salón de tal manera que quede una gran ronda. Utiliza esta estrategia para conversar sobre las diferentes representaciones del cuerpo humano. Los niños a medida que observan los dibujos, comentan las diferencias y semejanzas que encuentran.

Un $80 \%$ de los/as niños/as al dibujar su cuerpo marcan solo algunas de sus partes; como se puede observar en la Figura 1, la niña no marca las cejas ni las pestañas. Los dedos no tienen una forma determinada, ni tampoco tiene en cuenta la cantidad.

\section{Figura 1}

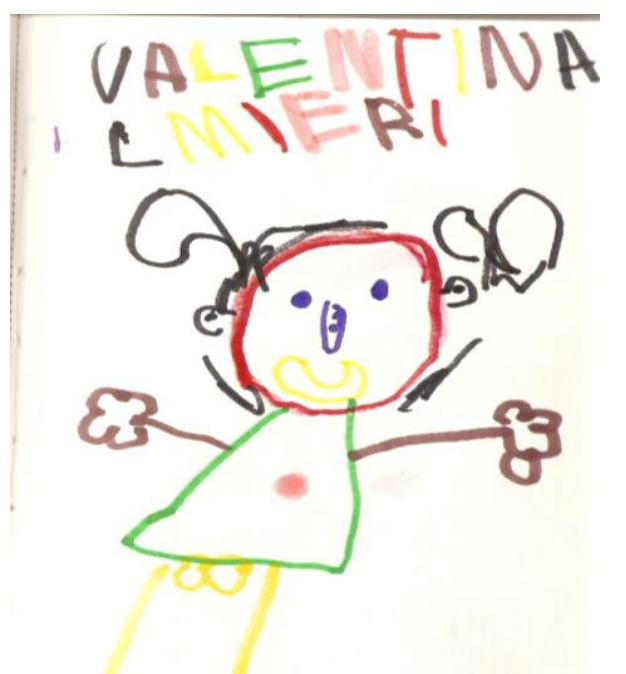

Estos dibujos no deben considerarse como representaciones inmaduras, ya que es evidente que en principio son un esquema, abstracción que refleja una amplia gama de estímulos muy complejos, en un proceso de ordenación mental (Vigotsky, 1993). El dibujo, en este caso como estrategia, resultó relevante para comenzar a complejizar 
los conocimientos de los niños, que al plantearse al inicio de un nuevo tema, ayuda a expresar individualmente los conceptos.

\section{Actividad III. Jugamos con un espejo}

En esta actividad, los niños y las niñas se sientan en grupos de cuatro. A medida que la docente recorre los bancos, le entrega a cada niño/niña un espejo y le permite, en un primer momento, jugar libremente con él. Así los niños apuntan a cualquier parte de su cuerpo, pero la mayoría se centran en observar sus ojos, su lengua, sus dientes. Luego la docente le entrega una hoja en blanco y les solicita que dibujen su rostro; el $80 \%$ de los/as niños/as no marcan las cejas, pestañas u orejas. Ante estos resultados, la docente le señala que se miren en el espejo y que completen los dibujos agregando las partes del rostro que faltan. El siguiente diálogo da cuenta que lo que sucedió en la sala:

Docente:- ¿Qué le marcaste, A5?

A5: - Los ojos, la boca y las orejas.

Docente:- Me parece que le faltan algunas partes.

A5: - No seño, si está todo.

Docente:- Fijate en el espejo para que compares lo que vos dibujaste y lo que te ves y te propongo que lo completes.

El niño mientras se observaba por el espejo dijo: ah, sí me faltó dibujar los dientes y mientras decía esto, dibujó los dientes; luego se descubrió en el espejo las cejas y las pestañas y por último las pecas.

Docente: - Ah, ahora sí A5, el dibujo de tu cara está más completa, pero de todas formas le falta algo, vos fíjate la cara ¿está sola? ¿O le sigue algo abajo?

El niño reconoce que no tuvo en cuenta el cuello, entonces lo representa con varios trozos de papel ubicándolo en el lugar correcto.

Figura 2

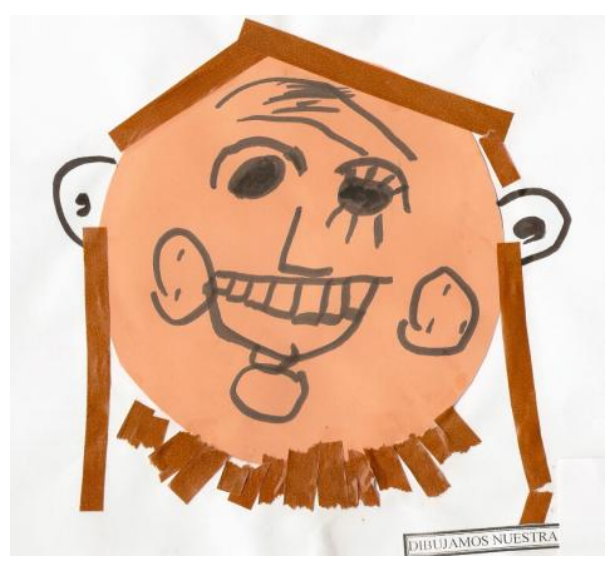

Del análisis de todos los dibujos de las caras se desprende que las niñas prestan más atención a los detalles como por ejemplo dibujan aros, cejas, pestañas. El espejo le permitió a niños/as enriquecer las observaciones y completar sus dibujos. Fueron capaces de aprender a planificar y regular la coherencia de sus dichos contrastándolos con la observación de sus caras en los espejos. 


\section{Actividad IV. El cuerpo por dentro}

La docente comienza la clase mostrándoles un esqueleto e interactúa con las niñas y niños a partir de preguntas ${ }^{3}$ :

A1: - Qué bueno que está eso.

A 2:- Es un esqueleto.

Docente: - Sí esto es un esqueleto, lo traje del laboratorio porque vamos a estudiar nuestro esqueleto. ¿Qué me pueden decir de los huesos, qué saben de los huesos?

(Los alumnos se encontraban sentados en ronda).

A 1: - Sí yo seño, se encuentran dentro del cuerpo.

A 2: - Son duros.

A 3: - Tenemos costillas- mientras decía esto se tocaba el tórax-.

Docente:- Qué huesos conocen.

A 1:- Huesos

A2:- Costillas.

D: - ¿Qué más?

A4:- Huesos.

A5: - Muchos huesos.

D:- Yo les voy a ir diciendo cómo se llaman algunos huesos y dónde están.

El hueso que se encuentra en la cabeza es el cráneo, después está la columna vertebral, es esta la que se ubica acá atrás, además están las costillas, en los brazos el húmero, el radio, el carpo en las manos; en las piernas el fémur, la tibia, el peroné, el tarso, metatarso y los dedos de los pies.

Luego la docente le entrega a cada niño/niña un esqueleto en cartón desarmado y le solicita que lo armen uniendo las partes utilizando para ello ganchos que les entrega por grupo. Una vez que logran armar el esqueleto completo observando el esqueleto que se encontraba en la sala de clase, la docente les formuló algunas preguntas orientativas para que reconocieran en la cabeza la ubicación de los ojos, la nariz, la cavidad bucal y el cráneo. También reconocen las costillas y la columna vertebral. En los apéndices superiores lograron diferenciar el brazo, la mano, los dedos y en las inferiores o piernas, el muslo, la pierna, el pie y los dedos.

La actividad continuó con la identificación de los huesos en su propio cuerpo; así la maestra, a través de consignas orales, pidió a niños y niñas que señalen en su cuerpo las partes del esqueleto armado por ellos. Hacia el final de la clase reconocen los distintos tipos de huesos a medida que observan el esqueleto y tocan su cuerpo. Comienzan a mencionar que hay huesos cortos como el de las vértebras, huesos largos como el de las piernas, chatos como las costillas. Finalmente como tarea la docente pide a los/as niños/niñas que conversen en sus hogares sobre el tema tratado en la sala.

\section{Actividad V. Seguimos con el cuerpo por dentro}

La maestra da continuidad a la actividad anterior preguntando: ¿Qué le dijo mamá o papá sobre los huesos? ¿Cómo son los huesos? ¿Qué huesos conocían sus padres? Los niños y las niñas comentaron que sus padres habían dicho que los huesos no eran todos iguales, que había huesos largos, cortos, anchos. Solo algunos recordaban unos pocos nombres de huesos y su ubicación, como el fémur.

\footnotetext{
${ }^{3}$ Con la letra $\mathrm{A}$ y el número se identifica a alumno/a
} 
Luego la docente entrega a los alumnos/as un papel carbónico y un hisopo con alcohol, ayudados con la imagen del esqueleto logran representar la estructura interna del cuerpo al cual le incorporan las articulaciones.

Figura 3

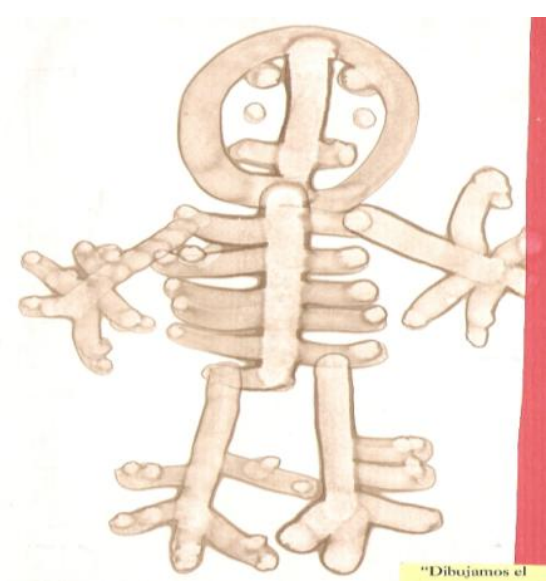

El uso de la observación y el intercambio verbal permitió a los niños/niñas encontrar nuevos datos y ampliar sus conocimientos; las actividades propuestas por la docente los puso en situaciones de aprendizaje que condujeron a encontrar estrategias para resolver las situaciones planteadas. Dibujar es una forma de representar una cosa, de hablar de algún aspecto del mundo exterior. El dibujo entendido como una imagen reproductora de lo que está presente, se caracteriza por la fidelidad al objeto que representa y constituye un soporte de los conceptos y las ideas. Juega un papel muy importante en el aprendizaje, puesto que es un lazo de unión entre el pensamiento y la realidad, en la medida que se concretan los conceptos.

\section{Actividad VI. Representación de los huesos}

A los dos días la docente les hace entrega de una hoja en blanco y solicita que dibujen el contorno de su cuerpo. Una vez que terminan de dibujar, entrega a cada niño/niña cierta cantidad de tiras de papel teñidas de color amarillo y un pegamento por grupo. Indica que con ese material completen el cuerpo pegando las tiras de papel de tal manera que representen los huesos de su cuerpo.

Figura 4

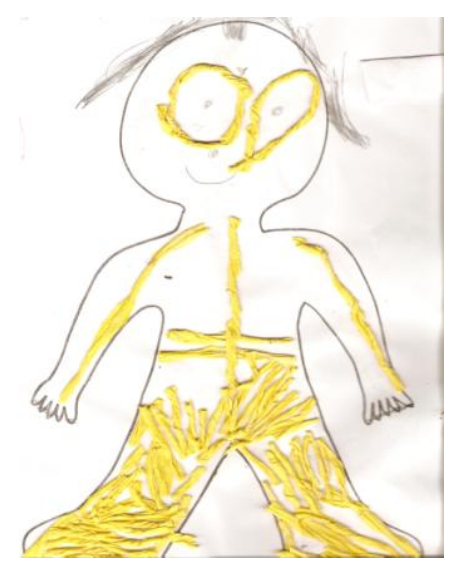


Los niños/niñas son capaces de representar con más precisión los detalles de los huesos y su respectiva ubicación. El planteamiento de este tipo de actividades de aprendizaje favoreció el desarrollo de las capacidades necesarias para avanzar en la construcción del conocimiento; son capacidades que se estimularon mediante la observación, el intercambio y de relaciones. La manipulación de material concreto, en este caso las tiras de papel, permitió que los niños y las niñas construyeran sus propios modelos de esqueleto. Es notable la precisión de las fosas oculares, como así también la disposición de los huesos de la columna. Resultó fundamental que los/as niños/niñas pudieran exponer, mediante las verbalizaciones, la significación de los dibujos y representaciones sus propios modelos, lo cual le permitió darle forma a su pensamiento y comunicarlo, conversando y dibujando.

\section{Actividad VII. Los órganos}

La docente entrega una hoja con un dibujo del contorno de una figura humana a cada uno de las/os niñas/niños y pide esta vez que representen los órganos que creen que hay dentro del cuerpo.

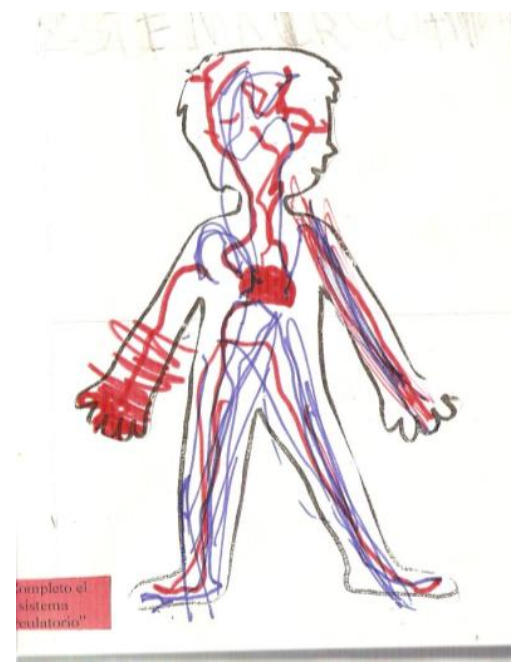

\section{Figura 5}

Cuando terminan de dibujar, la docente retira las producciones y las acomoda en un papel que se ubica sobre la pared y comienza a dialogar con los alumnos. Es el momento en que comienzan a intercambiar ideas, como por ejemplo el que dibujó el corazón explica el porqué de esa ubicación y su función.

Un 60 \% dibujan como únicos órganos el corazón, venas y los pulmones, un $30 \%$ representan el corazón, venas, los pulmones y riñones y un $10 \%$, además de los órganos mencionados incluyen el estómago y los intestinos.

En el momento del intercambio de ideas todos tienen la posibilidad de explicar sus representaciones gráficas. Comentan qué dibujaron, qué tuvieron en cuenta para ubicarlos en un determinado lugar y qué función cumplen. A continuación se transcribe un fragmento del intercambio dialógico en el que las/os niñas/niños verbalizan sus interpretaciones del modelo armado.

A12: - Yo dibujé el corazón en la parte izquierda del pecho porque mi papá me dijo que el corazón se ubica en la parte izquierda.

Docente: - ¿Qué crees que hace el corazón?

A12:- El corazón bombea sangre. 
A13:- Sí, el corazón late y permite que nosotros podamos vivir.

A12:- Sí, pero vivimos porque respiramos además.

Docente:- Sí, nosotros vivimos no solo porque late el corazón, sino porque además respiramos, comemos.

A14: - Sí, seño cuando respiramos el aire entra por la nariz y va a los pulmones y por la nariz sacamos el aire que está sucio.

A15: - Por los riñones tiramos el pis, que es agua que está sucia, que no le sirve al cuerpo.

Docente: - Muy bien, A15. Por los riñones eliminamos las sustancias tóxicas del cuerpo.

A partir de la interacción verbal, la docente favoreció la constatación de los distintos modelos identificados. En este intercambio de ideas, la intervención tuvo como propósito estimular las explicaciones, mostrar contradicciones en sus argumentos. Pozo (2010) sostiene que esta actividad de indagación configura en sí misma una situación de aprendizaje. Un factor clave para ello fue, desde nuestro punto de vista, haber tratado a los niños y niñas como verdaderas autoridades en el tema, lo que significa valorar las ideas infantiles y promover la participación activa en la construcción del conocimiento sobre el cuerpo humano.

\section{Consideraciones finales}

Después de la conversación, dibujar suele ser una de las actividades más frecuentes en las clases de Ciencias en el nivel inicial, pretendiendo que los escolares representen los elementos más destacados de las explicaciones, observaciones 0 lecturas realizadas. Esta experiencia de enseñar ciencias naturales en el nivel inicial da cuenta de cómo los conocimientos de los alumnos/as evolucionaron en la medida que se incorporan nuevas variables en el proceso de intervención didáctica. Al mismo tiempo, se le enseña a expresar sus ideas en un clima de respeto y de interés; hacer hablar al niño significa estar interesado por lo que dice, esto es, estar dispuesto a tenerlo en cuenta y por tanto a aceptar que estos conocimientos constituyen el punto de partida de toda la actividad escolar.

La escuela debe permitir el uso de los distintos tipos de lenguajes (dibujos, la pintura, las diversas técnicas plásticas) para expresarse, para repensar e incorporar experiencias realizadas, para confrontar modos diversos de conocer, para comunicar (Rassetto-Cañellas, 2009). En este caso, estas actividades escapan de la repetición y de los estereotipos y son valiosos materiales de trabajo para posteriores profundizaciones de los contenidos escolares.

Mediante las actividades propuestas, la docente promueve el desarrollo de procesos científicos tales como observación, descripción, formulación de preguntas, plantear hipótesis y predicciones, argumentar.

En cuanto a la observación, es fundamental tener en cuenta que es mucho más que mirar. Enseñar a observar requiere guiar a los alumnos a poner atención en los aspectos más importantes de lo que tiene ante sus ojos. En esta experiencia, la docente tenía claro de antemano el propósito de la observación: completar el esquema del cuerpo, el esqueleto con las tiras de papel de servilletas, comparan la forma y la ubicación de los diferentes huesos. De ahí en más todo fue más sencillo, por ejemplo, para el caso del rostro, cuando tuvieron que completar, en lugar de decirles lo que faltaba, les alcanzó un espejo para que ellos contrasten sus dibujos con lo que observaban en el espejo y agregar las partes ausentes. 
La otra cara de la observación es la descripción. En relación con la observación y la descripción hay que tener presente que diferentes observadores ven distintas cosas, cada uno guiado por los límites de sus propios sentidos y por los conocimientos previos que posee. En el nivel inicial, este proceso se realiza en forma oral; durante y/o luego de las observaciones, las/os niñas/os relatan lo que vieron, y en la interacción de los relatos, se incorporan nuevos aspectos que complejizan el dibujo.

La docente también les enseña a formular preguntas, esto implica que se pueda identificar y compartir las preguntas del tema que se está enseñando. Para enseñar a formular preguntas investigables presenta a los alumnos hechos no familiares 0 discrepantes; un ejemplo de ello fue cuando les presentó el esqueleto, las/os niñas/os se preguntaron ¿cómo son los huesos? ¿Qué formas tienen los huesos? ¿Por qué las costillas son consideradas huesos? Los alumnos proponen preguntas que surgen de la exploración del esqueleto que les resulta novedoso y llamativo. La docente retoma esas preguntas y los invita a ir más allá en su exploración, preguntándoles ¿dónde se ubican las costillas? ¿Qué órganos se encuentran cerca de las costillas? ¿Qué forma tienen las costillas?

Respecto del planteo de hipótesis y predicciones, entendidas desde la perspectiva escolar, los alumnos en todo momento tuvieron la oportunidad de expresar sus ideas, sus conocimientos previos. Desde la interacción, la docente capitaliza las discusiones y las retoma para promover en las niñas/os la formulación de anticipaciones que les permita pensar en relaciones entre hechos y fenómenos.

En la argumentación se trata de que los alumnos aprendan a ponerse de acuerdo sobre lo que observan, sobre cómo explicarlo y sobre a qué conclusiones arribar. Durante las clases, la docente permitió que los alumnos hicieran explícitos sus puntos de vistas e intercambien ideas, pidiéndoles que argumenten sus dichos. Por ejemplo, cuando se enseñan los huesos, los alumnos pudieron debatir sus ideas sobre si alrededor de los ojos había huesos. La maestra los fue guiando para conectar sus posturas con el esqueleto que observaban.

Esta experiencia pedagógica da cuenta que es posible enseñar ciencias naturales a niños/as pequeños/as, y que estos pueden comprender y resignificar conocimientos adquiridos en su contexto cultural. Las niñas y los niños complejizaron sus conocimientos sobre las partes del cuerpo, la cara, identificaron huesos, completaron la idea de esqueleto interno, y fueron capaces de señalar órganos internos estableciendo relaciones sencillas entre ellos. Se trata de plantear propuestas de enseñanzas que prioricen la interacción, la creatividad y la libertad para la expresión de las ideas infantiles. 


\section{BIBLIOGRAFÍA}

- Benlloch, M (1992). Ciencias en el parvulario. Una propuesta psicopedagógica para el ámbito de experimentación. Barcelona: Paidós educador.

- Casullo, M. (2006) El test gráfico del dibujo de la figura humana. Normas regionales. Buenos Aires: Editorial Guadalupe.

- Pozo, J (2010). Aprender a dibujar y a escribir. Noveduc: Buenos Aires.

- Rassetto, M. y Cañellas, A. (2009) Las conceptualizaciones infantiles sobre las magnitudes físicas y sus medidas. La necesidad del lenguaje en el proceso de enseñanza. En M. Rassetto y M. Massa (Comps.) Ciencias Naturales. Aportes desde la investigación educativa. (pp. 89 - 118) Educo: Neuquén.

- Tonucci, F. (1988) La escuela como investigación. Miño y Dávila Editores: Buenos Aires.

- Vygotsky, L. (1993). Obras Escogidas II. Madrid: Editorial Visor.

- Vigotsky, L (2009). El desarrollo de los procesos psicológicos superiores. Buenos Aires: Crítica.

\section{Documentos consultados}

Ley Provincial № 2444 (Provincia de Río Negro).

Diseño Curricular del Nivel Inicial (1996). 